\title{
A Cross-Cultural Perspective on the Blended Service Quality for Ride-Sharing Continuance
}

\author{
Wen-Lung Shiau, Zhejiang University of Technology, China \\ (iD) https://orcid.org/0000-0001-7974-5168 \\ Hao Chen, Zhejiang University of Technology, China \\ Kuanchin Chen, Western Michigan University, USA \\ Yi-Hung Liu, Soochow University, Taiwan \\ Felix Ter Chian Tan, Business School, University of New South Wales, Australia
}

\begin{abstract}
This research aims to elucidate the service quality factors influencing customer satisfaction with ride-sharing services. Particularly, this research compares Chinese and US consumers to identify the influence of national culture on user attitudes. Empirical research was conducted via two online surveys in China and the US. Data were collected and analyzed using partial least squares (PLS) analysis. The results show that while the satisfaction of the Chinese ride-sharing consumers was affected primarily by reliability, followed by platform assurance and empathy, the satisfaction of American consumers was influenced mainly by the conditions of ride-sharing vehicles (tangibles). The PLS-MGA results indicate that satisfaction with ride-sharing services had a significantly stronger impact on American rather than on Chinese continuance intention. Managerial implications are provided.
\end{abstract}

\section{KEYWORDS}

Collectivism, Individualism, National Culture, Ridesharing, Service Quality, Servqual, Sharing Economy

\section{INTRODUCTION}

Ride-sharing, also called ride-hailing, has greatly changed the way we travel (Dong, Wang, Li, \& Zhang, 2018). It provides additional travel options, decreases pollution, and reduces congestion, travel time, and cost (Vanderschuren \& Baufeldt, 2018). Ride-sharing has been gaining momentum in the sharing economy with a few key players, such as DiDi (China) and Uber (U.S.), competing in the global market. The global ride-sharing market size was valued at 6.68 billion USD in 2017 and is expected to grow at a compound annual growth rate (CAGR) of 7.5\% by 2025 (Grand View Research, 2019). Despite the large market size, players in this market face a constant need to understand customers and competitors (Chasin, von Hoffen, Hoffmeister, \& Becker, 2018). However, consumers across different cultures may value aspects of service quality differently. A one-size-fits-all strategy will unlikely create the right appeal to all customers. Added to the complexity is that globalization has offered consumers more choices for ride-sharing, thus reducing switching cost. As such, service encounters and past experiences are important elements of service quality more than ever. 
The sharing economy is essentially a service economy. Although prior studies have stressed the importance of service quality in customer satisfaction for sharing-economy (Cheng, Fu, \& de Vreede, 2018; Priporas et al., 2017), their samples are usually limited to one country that cannot be easily generalized to a different culture. Studies that employed inter-cultural comparisons in service quality (Agarwal, Malhotra, \& Bolton, 2010; Diallo \& Seck, 2018) rarely touch on ride-sharing services. Therefore, it is important to understand the cross-cultural perspectives of ride-sharing for global ridesharing companies and regional providers that also attract international customers. In addition, service quality in ride-sharing is the result of service encounters with both technology platforms and human interactions. Therefore, this research expands SERVQUAL with both types of variables. Our study aims to elucidate technology and human service quality dimensions between two cultures and how they affect customer satisfaction. To achieve this goal, the following research questions were considered: (1) What are the key factors of ride-sharing service quality in determining customer satisfaction in China and the U.S.? (2) Does national culture, especially individualism/collectivism (IDV/COL) moderate the impact of satisfaction on continuance intention between China and the U.S.? This paper offers valuable theoretical contributions, as it extends the service quality theory, applies MICOM and PLS-MGA to compare Chinese and American ride-sharing attitudes and behaviors, and confirms the moderating role of IDV/COL in the relationship between satisfaction and continuance intention.

The rest of this paper is organized as follows: Section 2 discusses ride-sharing services, service quality, national culture, satisfaction, and continuance intention; Section 3 presents the proposed research model and hypotheses; Section 4 details the research methodology used in this study; Section 5 presents the research results and discussion; and Section 6 describes the implications for research and practice. Finally, we conclude the research and present the research limitations and future research opportunities.

\section{THEORETICAL BACKGROUAND}

\subsection{Ridesharing and Service Quality}

IT has facilitated sharing and created the new concept of the "sharing economy" (Belk, 2010, 2014). Cusumano (2017) describes sharing economy as a general principle of strangers gaining access to underutilized or idle assets through digital platforms. In sharing economy, collaborative consumption incorporates sharing, renting, swapping or trading of goods and services that provide experiential benefits of temporary ownership of goods (Tan et al. 2017).

As a part sharing economy, ride-sharing is defined as a travel mode in which a consumer requests a vehicle with a driver through an online platform, and travels a route similar to or partially overlaps that of the driver or other passengers (Vanderschuren \& Baufeldt,2018; Wang, Gu, Wang, \& Wang, 2019). Ride-sharing platforms can help to deliver new commercial services and offerings, which enables new forms of consumption and, subsequently, disrupts the incumbent taxi industry. (Tan et al. 2017). People use ride-sharing services for reasons such as social-emotional benefits, economic benefits (Boateng, Kosiba, \& Okoe, 2019; Wang, Gu, et al., 2019), environmental benefits (Mattia, Guglielmetti Mugion, \& Principato, 2019), and risk (Ma, Zhang, Ding, \& Wang, 2019; Wang, Gu, et al., 2019). Research has discussed how ride-sharing companies improve their service quality to deliver consumer benefits (Cheng et al., 2018; Su, Nguyen-Phuoc, \& Johnson, 2019). Few have explored how culture plays a role in quality perception for ride-sharing.

Service quality is consumers' judgment of services based on the comparison between expected service and perceived service (Parasuraman, Zeithaml, \& Berry, 1985). Good service quality can improve the corporate image, retain existing customers, attract new customers, improve profitability and enhance competitive advantage (Kang \& James, 2004; Reichheld \& Sasser, 1990). SERVQUAL, one of the most popular service quality frameworks, divides service quality into five dimensions: tangibles, reliability, responsiveness, assurance, and empathy (Parasuraman, Berry, \& Zeithaml, 
1991; Parasuraman et al., 1988). SERVQUAL has been empirically validated across a variety of contexts, including tourism (Ahmad, Ahmad, \& Papastathopoulos, 2019), banking (Pakurár, Haddad, Nagy, Popp, \& Oláh, 2019), public services (Ocampo et al., 2019), healthcare (Ayaad et al., 2019; Chang et al, 2019), green products (Souri, Sajjadian, Sheikh, \& Sana, 2018), and airport services (Hong, Choi, \& Chae, 2020). Increasingly SERVQUAL is used to examine service quality in the electronic contexts (Huang, Lin, \& Fan, 2015; Parasuraman, Zeithaml, \& Malhotra, 2005; Santos, 2003). Most studies using SERVQUAL lumped system quality and physical human service quality together. However, DeLone \& McLean (2003) argued service quality is a separate construct from system quality and information quality.

Prior studies have explored service quality of bicycle sharing (Shao, Li, Guo, \& Zhang, 2020), space sharing (Cristobal-Fransi, Hernández-Soriano, Ferrer-Rosell, \& Daries, 2019; Priporas et al., 2017), and ride sharing (Su et al., 2019; Cheng et al., 2018). Despite some early interests in service quality of ride-sharing (e.g., Su et al. and Cheng et al.), research in this context has primarily adopted either a self-developed instrument away from the traditional treatment of service quality dimensions (e.g., Cheng et al) or treated service quality as a uni-dimensional construct (e.g., Su et al). Neither the dimensionality, nor the interwoven relationships of the dimensions of SERVQUAL have been reported for the ride-sharing shared economy. Key service quality research in sharing economy is summarized in Table 1. Ride-sharing is a unique context compared to several of those reported in Table 1 in that the service experience is derived from both physical encounters and online facilitating platforms. Thus, measurements that concern primarily physical encounters (such as the one used in $\mathrm{Su}$ et al. and source their scale was adapted from) can be further extended to cover both online and physical experiences for ride-sharing. Our study aims to fill this gap.

\subsection{National Culture and Consumer Behavior}

Hofstede (2001) describes culture as the collective programming of the mind that distinguishes the members of one group from another (p9). In Hofstede (2001) and their previous studies, national culture is seen to have five dimensions: power distance (PDI), uncertainty avoidance (UAI), individualism/ collectivism (IDV/COL), masculinity/femininity (MAS/FEM), and long-term/short-term orientation (LTO/STO). Although prior studies have explored the impact of culture on sharing economy (Davidson, Habibi, \& Laroche, 2018), most research on sharing economy has been conducted in Western countries with limited attention to East Asian societies. Comparison of cultural differences is necessary to help delineate discrepancies in theory applications for sharing economy (Cheng, 2016). China and U.S. are exemplary representations of eastern and western cultures that are seen to be different across multiple cultural dimensions (Chen \& Zahedi, 2016). Therefore, this research focuses on how national culture influences customers' attitudes between the two countries.

In prior studies, IDV has been widely discussed as one of Hofstede's cultural dimensions (Oyserman, Coon, \& Kemmelmeier, 2002). IDV refers to the degree to which a society emphasizes the role of an individual (Hofstede, 2001). While individualist societies emphasize rights above duties, concern for oneself and one's immediate family, and focus on self-actualization, collectivist societies stress on belonging, harmony, and predetermined opinions and in-group votes (Hofstede, 1980, 2001, 2011). Various prior studies have focused on the influence of IDV/COL on consumer attitudes and behaviors in the cross-cultural analyses (Agarwal et al., 2010; Frank, Enkawa, \& Schvaneveldt, 2015; Franque, Oliveira, Tam, \& Santini, 2020; Wen, Qin, Prybutok, \& Blankson, 2012). However, the results have been contradictory. While some argue that the magnitude of the impact of satisfaction on continuance intention is significantly larger for collectivists than for individualists (Agarwal et al., 2010; Wen et al., 2012), others maintain that individualism enhances the effect of customer satisfaction on continuance intention (Frank et al., 2015). Franque et al. (2020) even found no difference between individualist and collectivist cultures. Furthermore, few have studied the influence of IDV/COL on users' attitudes and behaviors toward service quality in sharing economy, especially ride-sharing, which requires a service to be a composite experience of online platforms and physical encounters. 
Table 1. Service quality studies in sharing economy

\begin{tabular}{|c|c|c|c|}
\hline Study & Domain & $\begin{array}{l}\text { Factors related to service } \\
\text { quality }\end{array}$ & Key findings \\
\hline Priporas et al. (2017) & Airbnb & $\begin{array}{l}\text { Assurance; } \\
\text { Tangibles; } \\
\text { Convenience; } \\
\text { Adequacy Service supply; } \\
\text { Understanding \& Caring }\end{array}$ & $\begin{array}{l}\text { Convenience and assurance } \\
\text { positively influence the perceived } \\
\text { service quality in remote Airbnb } \\
\text { lodgings. }\end{array}$ \\
\hline $\begin{array}{l}\text { Cristobal-Fransi, et al. } \\
\text { (2019) }\end{array}$ & $\begin{array}{l}\text { Collaborative } \\
\text { Accommodation } \\
\text { Platform }\end{array}$ & $\begin{array}{l}\text { Efficiency; } \\
\text { Reliability, } \\
\text { Privacy/Security; } \\
\text { Communication }\end{array}$ & $\begin{array}{l}\text { Efficiency, reliability, and privacy/ } \\
\text { security are critical contributors } \\
\text { to the measurement of quality of } \\
\text { a collaborative accommodation } \\
\text { portal. }\end{array}$ \\
\hline Shao et al. (2020) & Bicycle Sharing & $\begin{array}{l}\text { Location Reliability; } \\
\text { Prompt response; } \\
\text { Transaction Assurance; } \\
\text { Customization; } \\
\text { Vivid Appearance. }\end{array}$ & $\begin{array}{l}\text { Location reliability, prompt } \\
\text { response, customization, } \\
\text { transaction assurance and } \\
\text { vividness have different levels } \\
\text { of influences on customers' } \\
\text { confirmation of a bicycle-sharing } \\
\text { service. }\end{array}$ \\
\hline Su et al. (2019) & Ride-sharing & Perceived service quality & $\begin{array}{l}\text { Perceived service quality, } \\
\text { involvement, and satisfaction are } \\
\text { good predictors of passengers' } \\
\text { loyalty to ride-sourcing services. }\end{array}$ \\
\hline Cheng et al. (2018) & Ride-sharing & $\begin{array}{l}\text { Online service quality: } \\
\text { Structural assurance; } \\
\text { Platform responsiveness } \\
\text { Offline service quality: } \\
\text { Information congruity; } \\
\text { Competence } \\
\text { Empathy }\end{array}$ & $\begin{array}{l}\text { Structural assurance and platform } \\
\text { responsiveness are important } \\
\text { indicators of online service } \\
\text { quality that affect satisfaction and } \\
\text { loyalty. Information congruity, } \\
\text { competence, and empathy are } \\
\text { important indicators of offline } \\
\text { service quality that affect } \\
\text { satisfaction and loyalty. }\end{array}$ \\
\hline
\end{tabular}

Such a unique aspect of service quality is seen in Hung et al. (2012) where they showed that the interaction between technology and culture has a greater effect on communication quality and user satisfaction than either variable alone. Thus, it is necessary to study the role of IDV/COL in influencing consumers' attitudes and behaviors in the ride-sharing service context.

\subsection{Satisfaction and Continuance Intention}

Satisfaction has been linked to repurchase and use intention (Oliver, 1980; Mirkovski, Jia, Liu, \& Chen, 2018; Oliver, 1999; Shang \& Wu, 2017), even for the sharing economy (Huarng \& Yu, 2019; Shao et al., 2020). Continuance intention refers to the degree to which users believe they will repeatedly use ride-sharing services. If consumers are satisfied with their experiences with products or services, they are more likely to continue using the products or services (Bhattacherjee, 2001). Continuance intention has been adopted as a valid construct in offline and online shopping contexts (Kang, 2018; Mirkovski et al., 2018; Shang \& Wu, 2017). In the field of transportation sharing, researchers have focused mainly on users' intention to continue using free-floating car-sharing (Mattia et al., 2019) or bicycle sharing (Shao et al., 2020; Wang, Lin, \& Liu, 2019). However, few studies have discussed users' intention to continue using ride-sharing services. Thus, this research focuses on continuance intention to continue using ride-sharing services after the evaluation of service quality. 


\section{THE RESEARCH MODEL AND HYPOTHESES}

The research model integrates service quality, satisfaction, continuance intention, and IDV/COL. This model follows the perception-attitude-intention chain, which has been proven to be valid by theories explaining consumer behavior in information systems, such as the information systems success model (DeLone \& McLean, 2003). Figure 1 shows our proposed research model.

\section{Figure 1. Research model}

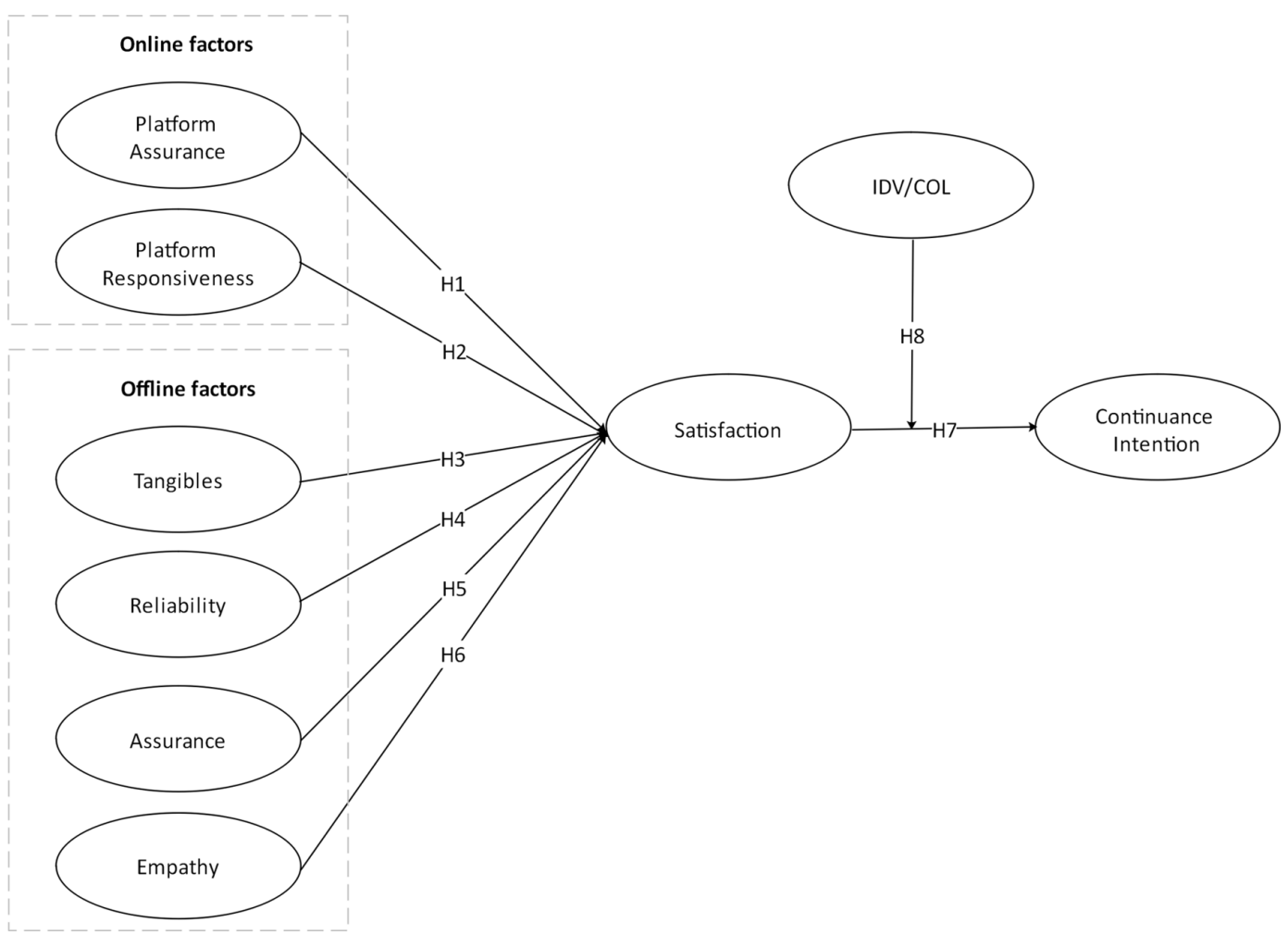

Satisfaction is affected by the value of services delivered to users (Heskett, Jones, Loveman, Sasser, \& Schlesinger, 1994). Previous research has suggested that users' perceptions of service quality affect their satisfaction (Cheng et al., 2018; Cristobal-Fransi, et al., 2019; Su et al., 2019). Platform assurance is a crucial factor in online service quality. Platform assurance refers to the ability of a platform to inspire the trust and confidence of customers. To build up customers' trust and confidence, most ride-sharing companies provide functions such as 'emergency help' on online platforms to ensure the personal safety of customers. Customers can use this function to contact police or an emergency contact, record the voice messages during the trips, and share their trips with friends. All these factors engender trust in ride-sharing services. Therefore, the following hypothesis is proposed:

H1. Platform assurance positively influences customer satisfaction with ride-sharing services.

Platform responsiveness means the ability of online representatives to respond to customers and help them solve problems quickly. Prior studies have confirmed the positive influence of platform or 
website responsiveness on customer satisfaction in the sharing economy context (Cheng et al., 2018; Huarng \& Yu, 2019; Ju, Back, Choi, \& Lee, 2019; Mousavi, Hazarika, Chen, \& Rienzo, 2020). If ride-sharing company representatives respond to customers' questions and help them as quickly as possible, customers will feel valued. In addition, customers who perceive that they are respected are more easily satisfied. Therefore, it is rational to hypothesize that platform responsiveness positively affects customer satisfaction as follows:

H2. Platform responsiveness positively influences customer satisfaction with ride-sharing services.

Tangibles refers to the physical equipment of a service (Parasuraman et al.,1988). Therefore, tangibles are related to the physical tools used to realize service processes. The positive relationships between tangibles and satisfaction have been empirically confirmed in various fields (Maioli, de Carvalho, \& de Medeiros, 2019; Omar, Ariffin, \& Ahmad, 2016). Maioli et al. (2019) argue that service providers should try to increase the tangibles of a service to satisfy customers. Tangibles are the physical image of offline ride-sharing services that customers use to evaluate service quality. Therefore, the following hypothesis is formulated:

H3. Tangibles positively influence customer satisfaction with ride-sharing services.

Reliability refers to the ability of the service provider to execute the promised service accurately and dependably. Reliability shows that the service provider endeavors to fulfill its promises and ensure good results. The positive influence of reliability on satisfaction has been empirically validated in prior studies (Meesala \& Paul, 2018; Omar et al., 2016; Pakurár et al., 2019). If drivers can take customers to the appointed destination accurately in a given time, the customers' needs are met, and they are satisfied with the service. Thus, we postulate the following hypothesis:

H4. Reliability positively influences customer satisfaction with ride-sharing services.

Assurance refers to the knowledge, competence, and good manners of employees in building trust with customers (Parasuraman et al., 1985). Prior research has exemplified the positive relationship between assurance and customer satisfaction (Kuswanto, Sundari, Harmadi, \& Hariyanti, 2020; Omar et al., 2016). In the ride-sharing context, ride-sharing drivers should not only be reliable, but also have the knowledge, courtesy, and ability to inspire customers to trust them. When drivers can assure customers of safe, and comfortable trips, customers would feel satisfied. Thus, we propose the following hypothesis:

H5. Assurance positively influences customer satisfaction with ride-sharing services.

Empathy is defined as offline entities' personality and benevolence to the customers (Cheng et al., 2018). Perceived empathy means the extent to which customers feel that the service provider values their personal needs and provides them with individualized concern (Parasuraman et al., 1988). Prior research has argued that when consumers perceive empathy from service providers, their impression of the service quality is confirmed, and they tend to be satisfied (Cheng et al., 2018; Omar et al., 2016; Shao et al., 2020). Empathy is also crucial for ride-sharing services. Although the main needs of customers are shown in their orders, there are occasional exceptions. Customers appreciate drivers who are empathetic, act in the customers' best interest, and try their best to help them. Thus, we propose the following hypothesis:

H6. Empathy positively influences customer satisfaction with ride-sharing services. 
According to ECT, satisfaction with products or services is the main motive for continuing to use them (Oliver, 1980). Satisfied consumers are more willing to repeatedly use services, while dissatisfied consumers may terminate the current service and switch to an alternative service. In the IS context, satisfaction enhances users' intention to continue to use the same system (Bhattacherjee, 2001; Brown, Venkatesh, \& Goyal, 2014; Limayem, Hirt, \& Christy, 2007). Similarly, in the sharing economy context, the effect of satisfaction on continuance intention has also been explored in many prior studies. Shao et al. (2020) find that user satisfaction contributes to bicycle-sharing. Huarng \& Yu (2019) also confirm the importance of satisfaction for Airbnb users' continuance intention. Similar results are also revealed for on-demand ride services (Malik \& Rao, 2019). Therefore, we hypothesize the following:

H7. Satisfaction positively affects ride-sharing continuance intention.

Individualists tend to express their own feelings of satisfaction or dissatisfaction unreservedly (Markus \& Kitayama, 1991). Therefore, individualists are more likely to continue using ride-sharing services when they feel satisfied with their ride-sharing service experiences. In addition, individualists usually have higher expectations of service quality (Donthu \& Yoo, 1998), and are therefore more difficult to satisfy. Prior studies have validated the moderating effects of IDV/COL on the relationship between satisfaction and continuance intention (Alcántara-Pilar et al., 2017; Frank et al., 2015). Based on the above discussion, we propose the following hypothesis:

H8. The impact of satisfaction on continuance intention is higher for individualists than for collectivists.

\section{RESEARCH METHODOLOGY}

\subsection{Instrument Development}

This study aims to model users' continuance intention in relation to ride-sharing services. All measurement items are also adapted from prior studies. Platform assurance and tangibles were adapted from Priporas et al. (2017), platform responsiveness and empathy were from Cheng et al. (2018), reliability and assurance were from Parasuraman et al. (1988), satisfaction was from Wang, et al. (2019) and finally continuance intention was adapted from Bhattacherjee (2001).

All measurement items were translated from English to Chinese by a senior professor and translated back to English by another senior professor for several rounds to ensure the accuracy of the items. Additionally, a pilot test with 13 experienced Chinese ride-sharing users and 8 experienced American ride-sharing users was performed to check the length, semantics, constructs, and format of the questionnaire items. A seven-point Likert scale was used for all items, with scores ranging from 1 (strongly disagree) to 7 (strongly agree). The measurement items are presented in Table 3. Consistent with the original SERVQUAL, reflective indicators are used for service quality dimensions (Parasuraman et al., 1988).

\subsection{Measurement Invariance of Composite Models}

Measurement invariance is necessary to reach meaningful and valid conclusions when conducting PLSSEM multigroup analysis (Henseler, Ringle, \& Sarstedt, 2016). The outcomes of group comparisons can be distorted unless researchers establish the measurement invariance before comparing different groups of samples. To determine measurement invariance, Henseler et al. (2016) propose a three-step procedure to assess measurement invariance in composite modeling, such as PLS path modeling. The measurement invariance procedure of composite models (MICOM) consists of configural invariance, compositional invariance, and the equality of composite mean values and variances. If configural and compositional invariance are established, partial measurement invariance is established, if not, 
no measurement invariance is established. If the equality of composite mean values and variances is established in addition to the establishment of partial measurement invariance, full measurement invariance is shown (Henseler et al., 2016).

This study is cross-cultural research, therefore, we used translation and back-translation techniques, and assessed the face and expert validity to ensure that the indicators across the Chinese and American groups were identical. Furthermore, we treated the collected Chinese and American samples in the same way, including coding, reverse coding, standardization, and missing value treatment. Finally, we used identical algorithm settings for both groups in the SEM software. Thus, configural invariance was established (Step 1). Compositional invariance (Step 2) and the equality of composite mean values and variances (Step 3) were analyzed with SmartPLS 3. We provide more details in the results section.

\subsection{Survey Administration}

The survey consisted of two parts: demographics and measurement scales. A screening question was used to ensure that the participants had experience with ride-sharing services, and those who did not use ride-sharing services were excluded. Two online surveys were launched in SOJUMP (China) and SurveyMonkey (US). Global reach is a huge advantage of online surveys (Evans \& Mathur, 2018), which are especially suitable for international research. The collected data were analyzed with SPSS and partial least squares (PLS). SPSS was used to analyze the demographic information and ridesharing experience of the respondents. Covariance-based structural equation modeling (CB-SEM) uses the maximum likelihood to estimate models and requires normally distributed data. In contrast, partial least squares structural equation modeling (PLS-SEM) has several advantages over CB-SEM in the situations such as nonnormal distributions, complex models, and small sample sizes (Hair, Risher, Sarstedt, \& Ringle, 2019; Khan et al., 2019; Shiau \& Chau, 2016; Shiau, Sarstedt, \& Hair, 2019). We used PLS because it worked efficiently with the complex model and small sample size in this study (Gefen, Rigdon, \& Straub, 2011; Hair et al., 2019; Khan et al., 2019; Shiau \& Chau, 2016; Shiau et al., 2019).

\section{RESTULTS AND DISCUSSION}

\subsection{Descriptive Statistics}

The target samples were people with experience of ride-sharing services. We excluded respondents without ride-sharing experience as well as careless respondents. Finally, a total of 376 responses were collected and included in the analysis. Of the 376 respondents, 237 were Chinese, and 176 were women (46.8\%). The majority of the respondents were aged under 25 (38.3\%), and most had more than one year of ride-sharing experiences (33.8\%). Table 2 presents the profile of the complete data of the ride-sharing users.

\subsection{Measurement Model}

\subsubsection{Measurement Model of Complete Data}

According to the two-step approach recommended by Anderson and Gerbing (1988), the measurement model was first examined for construct reliability and validity, followed by the structural model evolution for path coefficients between constructs, and variance of endogenous latent variables explained by exogenous latent variables. SmartPLS 3 was used to estimate the measurement model and structural model.

Construct reliability and validity were tested in the measurement model. Factor loadings with values higher than 0.5 indicated item reliability (Hair, Black, Babin, Anderson, \& Tatham, 2006). Table 5 shows that the factor loadings of the constructs all exceeded 0.6 and were significant $(\mathrm{p}<0.001)$. Therefore, all items in our study were found to be acceptable. Standardized root mean 
Table 2. Demographics

\begin{tabular}{|c|c|c|c|}
\hline \multirow[t]{2}{*}{ User profile } & \multirow[t]{2}{*}{ Categories } & \multicolumn{2}{|c|}{ Sample } \\
\hline & & Frequency & Percentage $(\%)$ \\
\hline \multirow[t]{2}{*}{ Gender } & Male & 200 & 53.2 \\
\hline & Female & 176 & 46.8 \\
\hline \multirow[t]{6}{*}{ Age } & $<25$ & 144 & 38.3 \\
\hline & $26-29$ & 78 & 20.7 \\
\hline & $30-34$ & 81 & 21.5 \\
\hline & $35-39$ & 46 & 12.2 \\
\hline & $40-49$ & 19 & 5.1 \\
\hline & $>50$ & 8 & 2.2 \\
\hline \multirow[t]{3}{*}{ Education level } & Associate degree (Below) & 48 & 12.8 \\
\hline & Bachelor's degree & 275 & 73.1 \\
\hline & Master's degree (above) & 53 & 14.1 \\
\hline \multirow{4}{*}{$\begin{array}{l}\text { Experience with ride- } \\
\text { sharing services }\end{array}$} & 1 year or less & 86 & 22.9 \\
\hline & More than 1 year to 3 years & 127 & 33.8 \\
\hline & More than 3 years to 5 years & 119 & 31.6 \\
\hline & More than 5 years & 44 & 11.7 \\
\hline \multirow[t]{5}{*}{ Frequency } & A few times a week & 111 & 29.5 \\
\hline & About once a week & 53 & 14.1 \\
\hline & A few times a month & 111 & 29.5 \\
\hline & Once a month & 23 & 6.1 \\
\hline & Less than once a month & 78 & 20.8 \\
\hline
\end{tabular}

square residual (SRMR) is a model fit parameter for PLS-SEM, and a value lower than 0.10 shows a good fit (Henseler et al., 2014). In this study, the SRMR value was 0.066, which indicated an acceptable model. The reliability, convergent validity, and discriminant validity were also assessed to validate the measurement model. Composite reliability values exceeding 0.70 indicated the internal consistency of the measurement model (Bagozzi \& Yi, 1988). Table 5 shows that all the composite reliability values were above 0.70 , indicating reliable constructs. The average variance extracted (AVE) of each construct should exceed 0.50 (Fornell \& Larcker, 1981). Table 3 shows that the AVE values of all constructs were above 0.50 .

Based on the analysis of the discriminant validity, the results according to the Fornell-Larcker criterion indicate discriminant validity, because the square root of the AVE value for each construct is greater than its correlations with the other constructs (Fornell \& Larcker, 1981). In addition, the HTMT ratio is an alternative method for evaluating discriminant validity and discriminant validity is achieved between two reflective constructs if the HTMT ratio is below 0.90. (Henseler, Ringle, \& Sarstedt, 2015). The highest HTMT ratio was 0.810 , which showed discriminant validity. The results of discriminant validity are presented in Table 4 . In conclusion, all these results show that the research model had acceptable reliability and validity for the complete data. When checked separately, the China and U.S. sub-samples also met the above criteria for discriminant validity. 
Table 3. Measurement model evaluation (complete sample)

\begin{tabular}{|c|c|c|c|c|c|c|c|}
\hline Construct & Item & Item mean & SD & Loading & t-value & CR & AVE \\
\hline \multirow[t]{4}{*}{ PAS } & PAS1 & 5.503 & 1.1600 & 0.753 & $21.234 * * *$ & \multirow[t]{4}{*}{0.868} & \multirow[t]{4}{*}{0.622} \\
\hline & PAS2 & 5.598 & 1.1650 & 0.757 & $22.559 * * *$ & & \\
\hline & PAS3 & 5.447 & 1.2130 & 0.812 & $29.643 * * *$ & & \\
\hline & PAS4 & 5.295 & 1.1940 & 0.830 & $34.742 * * *$ & & \\
\hline \multirow[t]{3}{*}{ PRE } & PRE1 & 5.111 & 1.3670 & 0.842 & $25.642 * * *$ & \multirow[t]{3}{*}{0.890} & \multirow[t]{3}{*}{0.729} \\
\hline & PRE2 & 4.223 & 1.3870 & 0.812 & $18.985^{* * *}$ & & \\
\hline & PRE3 & 4.573 & 1.4640 & 0.905 & $46.585^{* * * *}$ & & \\
\hline \multirow[t]{3}{*}{ TAN } & TAN1 & 5.875 & 0.9360 & 0.743 & $14.789 * * *$ & \multirow[t]{3}{*}{0.828} & \multirow[t]{3}{*}{0.617} \\
\hline & TAN2 & 5.753 & 0.9650 & 0.789 & $22.621 * * *$ & & \\
\hline & TAN3 & 5.835 & 0.9670 & 0.822 & $30.745^{* * *}$ & & \\
\hline \multirow[t]{3}{*}{ REL } & REL1 & 5.939 & 0.8990 & 0.807 & $28.416^{* * *}$ & \multirow[t]{3}{*}{0.803} & \multirow[t]{3}{*}{0.577} \\
\hline & REL2 & 5.912 & 0.9680 & 0.747 & $17.856^{* * *}$ & & \\
\hline & REL3 & 5.678 & 1.0160 & 0.722 & $16.447 * * *$ & & \\
\hline \multirow[t]{4}{*}{ ASS } & ASS1 & 5.410 & 1.2100 & 0.817 & $29.026^{* * * *}$ & \multirow[t]{4}{*}{0.860} & \multirow[t]{4}{*}{0.606} \\
\hline & ASS2 & 5.412 & 1.1290 & 0.821 & $36.886^{* * *}$ & & \\
\hline & ASS3 & 5.859 & 0.8980 & 0.764 & $25.163^{* * *}$ & & \\
\hline & ASS4 & 5.287 & 1.2210 & 0.706 & $18.457 * * *$ & & \\
\hline \multirow[t]{3}{*}{ EMP } & EMP1 & 5.213 & 1.1820 & 0.855 & $42.284^{* * * *}$ & \multirow[t]{3}{*}{0.874} & \multirow[t]{3}{*}{0.698} \\
\hline & EMP2 & 5.441 & 0.9770 & 0.848 & $39.474 * * *$ & & \\
\hline & EMP3 & 4.931 & 1.1740 & 0.802 & $30.042 * * *$ & & \\
\hline \multirow[t]{3}{*}{ SAT } & SAT1 & 5.790 & 0.8880 & 0.854 & $42.829 * * *$ & \multirow[t]{3}{*}{0.880} & \multirow[t]{3}{*}{0.710} \\
\hline & SAT2 & 5.771 & 0.8820 & 0.841 & $38.966 * * *$ & & \\
\hline & SAT3 & 5.681 & 0.9780 & 0.832 & $38.416^{* * *}$ & & \\
\hline \multirow[t]{3}{*}{$\mathrm{CI}$} & CI1 & 6.053 & 0.9930 & 0.877 & $64.018 * * *$ & \multirow[t]{3}{*}{0.872} & \multirow[t]{3}{*}{0.695} \\
\hline & $\mathrm{CI} 2$ & 5.322 & 1.3130 & 0.759 & $19.111^{* * *}$ & & \\
\hline & $\mathrm{CI} 3$ & 6.189 & 1.2110 & 0.861 & $42.228 * * *$ & & \\
\hline \multicolumn{8}{|c|}{ 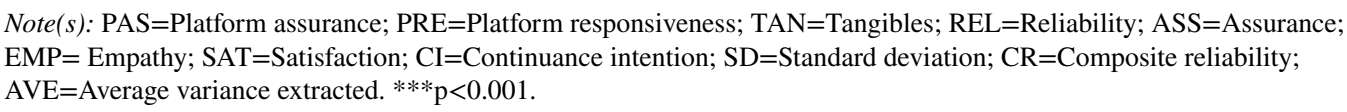 } \\
\hline
\end{tabular}

\subsubsection{Measurement Model of Chinese and American Data}

We also examined the measurement model for the Chinese data and American data separately. In this study, the SRMR values were 0.075 for the Chinese data and 0.081 for the American data, which indicated an acceptable model. Table 5 shows that all the composite reliability values for the Chinese and American data were above 0.70, indicating reliable constructs. The AVE values of all constructs were above 0.50 for the Chinese and American data, indicating convergent validity. In sum, all these results show that the research model had acceptable reliability and validity for both the Chinese and American data. 
Table 4. Discriminant validity (complete sample)

\begin{tabular}{|l|l|l|l|l|l|l|l|l|l|l|l|l|l|l|l|l|l|}
\hline \multicolumn{10}{|c|}{ Fornell-Larcker Criterion } & \multicolumn{10}{|c|}{ HTMT } \\
\hline & PAS & PRE & TAN & REL & ASS & EMP & SAT & CI & & PAS & PRE & TAN & REL & ASS & EMP & SAT & CI \\
\hline PAS & 0.789 & & & & & & & & PAS & & & & & & & & \\
\hline PRE & 0.336 & 0.854 & & & & & & & PRE & 0.407 & & & & & & & \\
\hline TAN & 0.354 & 0.228 & 0.785 & & & & & & TAN & 0.718 & 0.413 & & & & & & \\
\hline REL & 0.361 & 0.282 & 0.523 & 0.760 & & & & & REL & 0.497 & 0.379 & 0.767 & & & & & \\
\hline ASS & 0.386 & 0.355 & 0.531 & 0.567 & 0.778 & & & & ASS & 0.476 & 0.436 & 0.718 & 0.791 & & & & \\
\hline EMP & 0.309 & 0.266 & 0.393 & 0.482 & 0.630 & 0.835 & & & EMP & 0.368 & 0.322 & 0.810 & 0.670 & 0.810 & & & \\
\hline SAT & 0.408 & 0.299 & 0.495 & 0.559 & 0.514 & 0.495 & 0.842 & & SAT & 0.504 & 0.366 & 0.650 & 0.767 & 0.650 & 0.623 & & \\
\hline CI & 0.505 & 0.322 & 0.314 & 0.410 & 0.737 & 0.247 & 0.639 & 0.834 & CI & 0.649 & 0.395 & 0.413 & 0.561 & 0.469 & 0.313 & 0.792 & \\
\hline
\end{tabular} $\begin{aligned} & \text { Note(s): PAS=Platform assurance; PRE=Platform responsiveness; TAN=Tangibles; REL=Reliability; ASS=Assurance; EMP= } \\
& \text { Empath; SAT=Satisfaction; CI=Continuance intention. }\end{aligned}$

\subsection{Structural Model of Complete Data}

Following the assessment of the measurement model, the structural model was evaluated. It is vital to identify the significance of the hypothesized paths and the variance explained ( $\mathrm{R}$ square) of the endogenous variables. For the complete data, the results showed a variance of $40.9 \%$ for continuance intention and a variance of $44.4 \%$ for satisfaction (see Figure 2). The results of the hypothesis testing are presented in Table 6.

\subsection{Structural Model of Chinese and American Data}

For the Chinese data, the results showed a variance of $35.5 \%$ for continuance intention and a variance of $49.5 \%$ for satisfaction (see Figure 3). For the American data, the results showed a variance of 55.2\% for continuance intention and a variance of $51.0 \%$ for satisfaction (see Figure 4). The bootstrapping results showed that platform assurance, empathy, and reliability affected Chinese satisfaction but not American satisfaction. Tangibles significantly affected American satisfaction, but not Chinese satisfaction. Platform responsiveness and assurance had no influence on satisfaction among the Chinese and American users. Satisfaction influenced both Chinese and American continuance intention. The results of the hypothesis testing are presented in Table 7.

\subsubsection{Platform Factors on Satisfaction}

Platform assurance had a significant influence on satisfaction for the Chinese sample (H1: $\beta=0.220$, $\mathrm{p}<0.01)$, but not for the American sample $(\mathrm{H} 1: \beta=0.159, \mathrm{p}>0.05)$. This finding from the Chinese sample is consistent with prior studies that suggest that collectivists are generally more interdependent and seek assurance from people (Gudykunst et al., 1996; Markus \& Kitayama, 1991; Oyserman et al., 2002). In our case here, Chinese respondents sought the assurance from an extended network of people, including the service providers. Didi and other Chinese service providers implemented the 'emergency help' feature in response to major safety incidents. While Uber is not free from safety incidents, their safety tips web page still relies on an individual's self-awareness for protection. As a result, the individualist approach is practiced more in the U.S. than in China.

Ride-sharing platform responsiveness had no impact on satisfaction for either the Chinese $(\mathrm{H} 2: \beta=0.054, \mathrm{p}>0.05)$ or the American $(\mathrm{H} 2: \beta=0.132, \mathrm{p}>0.05)$ users. This finding is contrary to prior research, which have found that low platform responsiveness is a strong reason for dissatisfaction (Ju et al., 2019). Today's ride-sharing platforms are usually very responsive in terms of information sharing, status notification and many other events that are keys to the ride-sharing experience. Platform related issues are frequently resolved by automated support means (e.g., FAQ, chat bots, 
Table 5. Measurement model evaluation (China versus US)

\begin{tabular}{|c|c|c|c|c|c|c|c|}
\hline \multirow[t]{2}{*}{ Construct } & \multirow[t]{2}{*}{ Item } & \multicolumn{2}{|c|}{ Loading } & \multicolumn{2}{|c|}{ CR } & \multicolumn{2}{|c|}{ AVE } \\
\hline & & China & The US & China & US & China & US \\
\hline \multirow{4}{*}{ PAS } & PAS1 & $0.719 * * *$ & $0.702 * * *$ & \multirow{4}{*}{0.821} & \multirow{4}{*}{0.843} & \multirow{4}{*}{0.537} & \multirow{4}{*}{0.573} \\
\hline & PAS2 & $0.637 * * *$ & $0.755^{* * *}$ & & & & \\
\hline & PAS3 & $0.765^{* * *}$ & $0.760 * * *$ & & & & \\
\hline & PAS4 & $0.799 * * *$ & $0.808 * * *$ & & & & \\
\hline \multirow{3}{*}{ PRE } & PRE1 & $0.856^{* * *}$ & $0.784 * * *$ & \multirow{3}{*}{0.902} & \multirow{3}{*}{0.836} & \multirow{3}{*}{0.754} & \multirow{3}{*}{0.630} \\
\hline & PRE2 & $0.810^{* * *}$ & $0.754 * * *$ & & & & \\
\hline & PRE3 & $0.935^{* * *} *$ & $0.840 * * *$ & & & & \\
\hline \multirow{3}{*}{ TAN } & TAN1 & $0.746 * * *$ & $0.732 * * *$ & \multirow{3}{*}{0.813} & \multirow{3}{*}{0.858} & \multirow{3}{*}{0.591} & \multirow{3}{*}{0.669} \\
\hline & TAN2 & $0.778 * * *$ & $0.835 * * *$ & & & & \\
\hline & TAN3 & $0.783^{*} * *$ & $0.879 * * *$ & & & & \\
\hline \multirow{3}{*}{ REL } & REL1 & $0.761 * * *$ & $0.859 * * *$ & \multirow{3}{*}{0.766} & \multirow{3}{*}{0.851} & \multirow{3}{*}{0.522} & \multirow{3}{*}{0.657} \\
\hline & REL2 & $0.707 * * *$ & $0.817 * * *$ & & & & \\
\hline & REL3 & $0.697 * * *$ & $0.753 * * *$ & & & & \\
\hline \multirow[t]{4}{*}{ ASS } & ASS1 & $0.756^{* * *}$ & $0.888 * * *$ & \multirow{4}{*}{0.821} & \multirow{4}{*}{0.911} & \multirow{4}{*}{0.535} & \multirow{4}{*}{0.721} \\
\hline & ASS2 & $0.786^{* * *}$ & $0.888 * * *$ & & & & \\
\hline & ASS3 & $0.673^{* * *}$ & $0.881 * * *$ & & & & \\
\hline & ASS4 & $0.705^{* * *} *$ & $0.729 * * *$ & & & & \\
\hline \multirow[t]{3}{*}{ EMP } & EMP1 & $0.858 * * *$ & $0.862 * * *$ & & & & \\
\hline & EMP2 & $0.863 * * *$ & $0.817 * * *$ & 0.878 & 0.868 & 0.705 & 0.687 \\
\hline & EMP3 & $0.797 * * *$ & $0.806^{* * *}$ & & & & \\
\hline SAT & SAT1 & $0.824 * * *$ & $0.914 * * *$ & & & & \\
\hline & SAT2 & $0.766^{* * *}$ & $0.926 * * *$ & 0.844 & 0.926 & 0.644 & 0.807 \\
\hline & SAT3 & $0.816^{* * * *}$ & $0.853^{* * *}$ & & & & \\
\hline & CI1 & $0.862 * * *$ & $0.886 * * *$ & & & & \\
\hline CI & CI2 & $0.694^{* * *}$ & $0.747 * * *$ & 0.823 & 0.877 & 0.609 & 0.705 \\
\hline & $\mathrm{CI} 3$ & $0.776^{* * * *}$ & $0.878 * * *$ & & & & \\
\hline $\begin{array}{l}\text { Note }(s): \mathrm{PAS} \\
\mathrm{EMP}=\mathrm{Emp}\end{array}$ & $\begin{array}{l}\text { latform } \\
\text {; SAT }=\end{array}$ & $\begin{array}{l}\text { surance; Pl } \\
\text { tisfaction; }\end{array}$ & $\begin{array}{l}\text { latform resp } \\
\text { ontinuance i } \\
.001 \text {. }\end{array}$ & $\begin{array}{l}\text { hess; TAN } \\
\mathrm{n} ; \mathrm{SD}=\mathrm{St}\end{array}$ & $\begin{array}{l}\text { angible } \\
\text { ard dev }\end{array}$ & $\begin{array}{l}=\text { Reliabil } \\
\mathrm{CR}=\text { Com }\end{array}$ & $\begin{array}{l}\mathrm{ASS}=\mathrm{Assur} \\
\text { e reliability }\end{array}$ \\
\hline
\end{tabular}


Figure 2. Results of the structural model of complete data Note(s): ${ }^{*}=p<0.05 ; * * *=p<.001$.

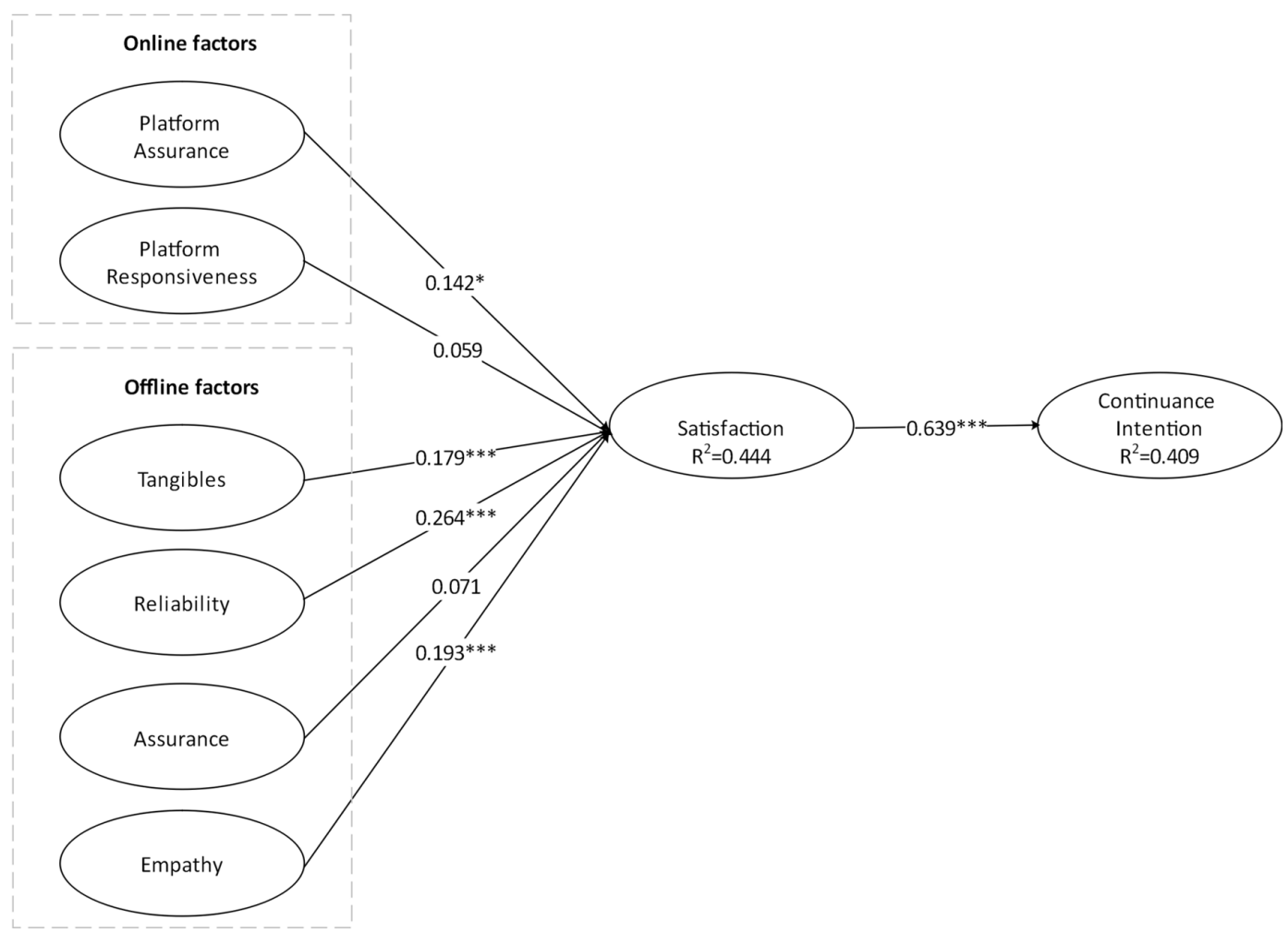

Table 6. Results of hypothesis testing (complete sample)

\begin{tabular}{|l|l|l|l|l|l|}
\hline \multicolumn{2}{|c|}{ Hypothesis relationships } & \multicolumn{1}{c|}{ Path coefficient } & \multicolumn{1}{c|}{ SD } & \multicolumn{1}{c|}{ T-value } & \multicolumn{1}{c|}{ Supported } \\
\hline H1 & PAS®SAT & $0.143^{*}$ & 0.062 & 2.291 & Yes \\
\hline H2 & PRE®SAT & 0.059 & 0.049 & 1.209 & NO \\
\hline H3 & TAN@SAT & $0.179 * * *$ & 0.055 & 3.289 & Yes \\
\hline H4 & REL®SAT & $0.264 * * *$ & 0.058 & 4.551 & Yes \\
\hline H5 & ASS®SAT & 0.071 & 0.065 & 1.094 & NO \\
\hline H6 & EMP®SAT & $0.193 * * *$ & 0.059 & 3.264 & Yes \\
\hline H7 & SAT®CI & $0.639 * * *$ & 0.042 & 15.234 & Yes \\
\hline
\end{tabular}

Note $(s)$ : PAS=Platform assurance; $\mathrm{PRE}=$ Platform responsiveness; TAN=Tangibles; REL=Reliability; ASS=Assurance; $\mathrm{EMP}=$ Empathy; SAT=Satisfaction; $\mathrm{CI}=$ Continuance intention; $\mathrm{SD}=$ Standard deviation. $* \mathrm{p}<0.05 ; * * * \mathrm{p}<0.001$. 
Figure 3. Results of the structural model of Chinese data Note(s): ** $=p<.011^{* * *}=p<.001$.

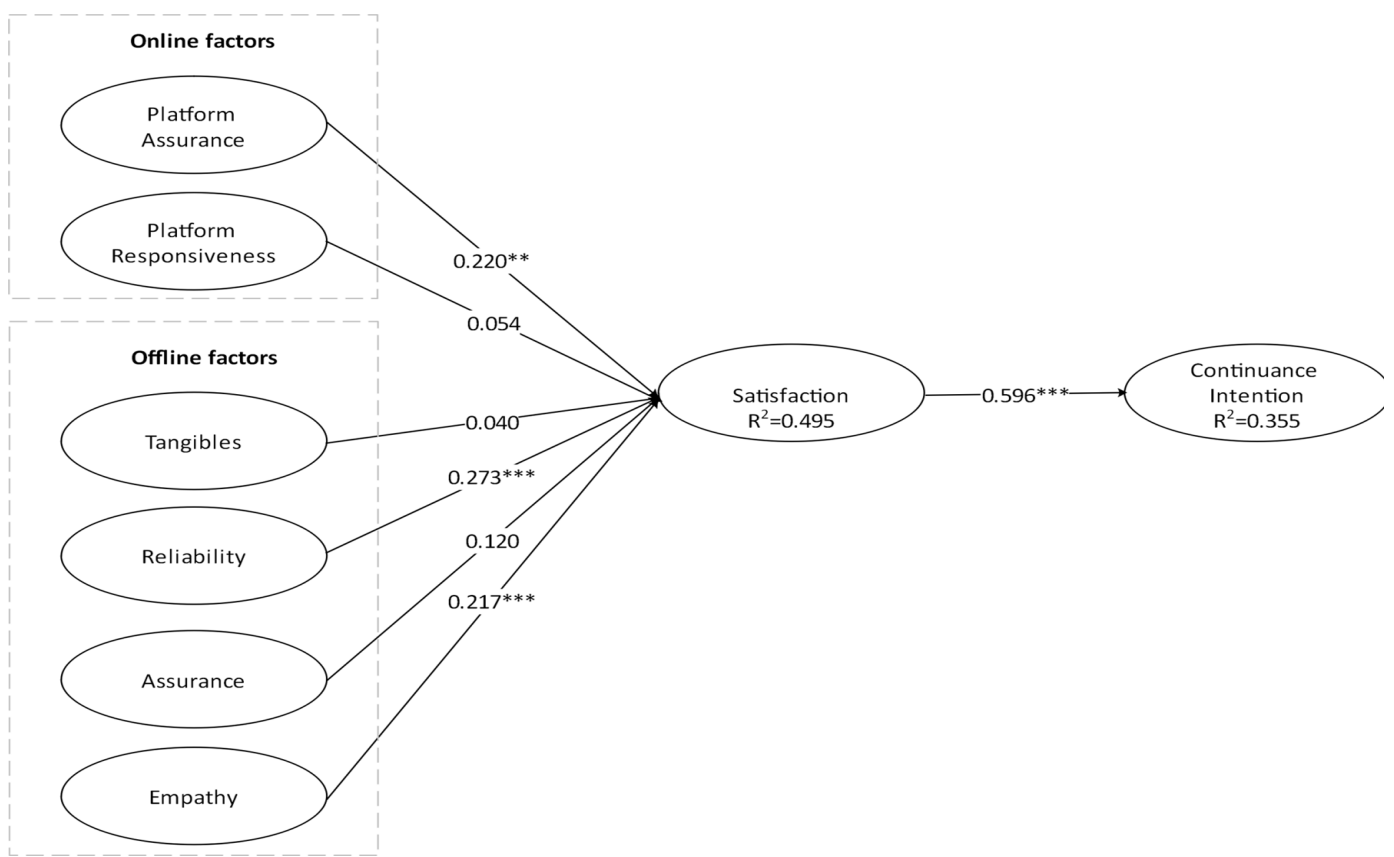

Figure 4. Results of the structural model of American data Note(s): ${ }^{* * *}=p<.001$.

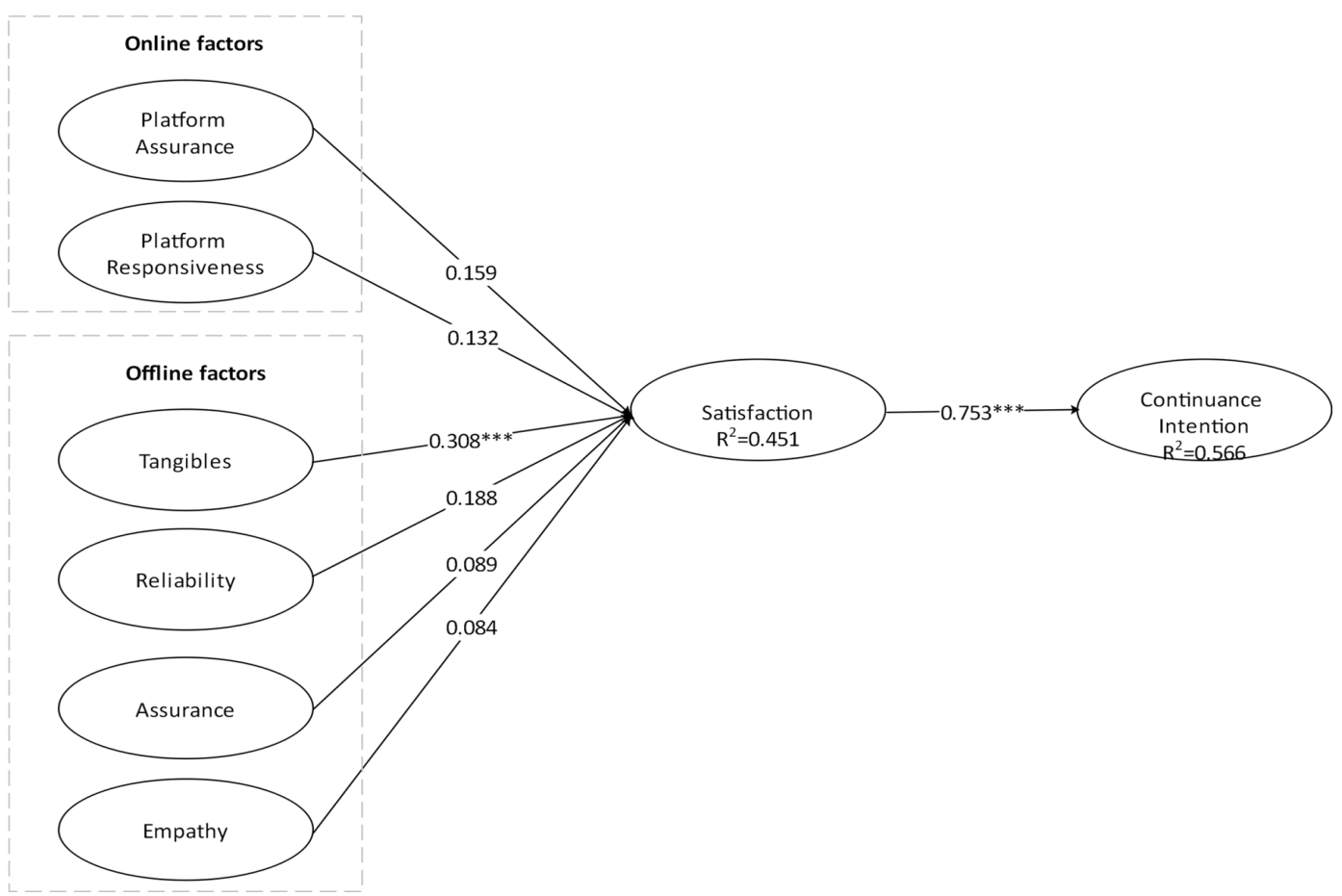


Table 7. Results of hypothesis testing (China versus US)

\begin{tabular}{|c|c|c|c|c|c|c|c|c|c|}
\hline \multicolumn{2}{|c|}{$\begin{array}{l}\text { Hypothesis } \\
\text { relationship }\end{array}$} & \multicolumn{2}{|c|}{ Path coefficient } & \multicolumn{2}{|r|}{ S. D. } & \multicolumn{2}{|c|}{ T-value } & \multicolumn{2}{|c|}{ Supported } \\
\hline & & China & the US & China & the US & China & the US & China & the US \\
\hline $\mathrm{H} 1$ & PAS@SAT & $0.220 * *$ & 0.159 & 0.072 & 0.086 & 3.057 & 1.856 & Yes & NO \\
\hline $\mathrm{H} 2$ & PRE®SAT & 0.054 & 0.132 & 0.053 & 0.086 & 1.004 & 1.541 & NO & NO \\
\hline $\mathrm{H} 3$ & TAN@SAT & 0.040 & $0.308 * * *$ & 0.080 & 0.093 & 0.493 & 3.304 & $\mathrm{NO}$ & Yes \\
\hline $\mathrm{H} 4$ & REL®SAT & $0.273 * * *$ & 0.188 & 0.075 & 0.112 & 3.639 & 1.672 & Yes & NO \\
\hline H5 & ASS®SAT & 0.120 & 0.089 & 0.090 & 0.097 & 1.336 & 0.913 & NO & NO \\
\hline H6 & EMP®SAT & $0.217 * * *$ & 0.084 & 0.062 & 0.108 & 3.515 & 0.78 & Yes & NO \\
\hline H7 & SAT®CI & $0.596 * * *$ & $0.753 * * *$ & 0.044 & 0.048 & 13.465 & 15.798 & Yes & Yes \\
\hline
\end{tabular}

etc.), stronger signals or short durations of customer support. Since modern ride-sharing platforms are quite efficient in the above forms of platform responsiveness, its role on satisfaction diminishes as compared with the effect from physical experiences with the driver and peer riders.

\subsubsection{Offline Physical Factors on Satisfaction}

Tangibles had no influence on users' satisfaction in the Chinese sample $(H 3: \beta=0.040, p>0.05)$, but had a statistically significant influence in the U.S. sample $(H 3: \beta=0.308, p<0.001)$. Although the results from the U.S. sample is consistent with existing studies (e.g., Malhotra, Agarwal, \& Shainesh, 2018), our findings highlight the preferential difference in the formulation of satisfaction between the two cultures.

The reliability of ride-sharing had a positive effect on the Chinese users' satisfaction $(H 4: \beta=0.273$, $\mathrm{p}<0.001$ ), but not so much for the American users ( $\mathrm{H} 4: \beta=0.188, \mathrm{p}>0.05)$. When Chinese users order a car through a ride-sharing platform, they expect the order to be fulfilled accurately and dependably by the driver who accepts the order. Ride-sharing drivers should not only be good at driving but also be proficient in the use of information technology. The pickup locations in the navigation are often not accurate; thus, most drivers would call the customers to confirm the exact pickup location, and then they rely on the navigation app to correctly drive the customers to their destinations. Thus, reliability has an additional layer of human touch. However, such human aspect of reliability may be less required for a longer history of ride-sharing development in the U.S. that has enabled technologies to better pinpoint the customer location. China's newly launched GPS BeiDou in June 2020 has promising capabilities of commercial value for ride-sharing and other applications.

Surprisingly, assurance had no impact on satisfaction for either the Chinese $(H 5: \beta=0.120, p>0.05)$ or the American $(\mathrm{H} 5: \beta=0.089, \mathrm{p}>0.05)$ users, which is contrary to prior research that confirms a positive relationship between assurance and satisfaction (Priporas et al., 2017). There may be third possible reasons for this. First, trust is the foundation of using ride-sharing, since consumers are asked to ride with strangers. Second, aspects of assurance, such as occupational knowledge, can be provided to automatic means (e.g., GPS). Third, ride-sharing companies employ procedures to verify driver qualifications to instill consumer confidence. The statistical insignificance does not mean assurance is not valued. Instead, aspects of assurance are enough to explain variations of service satisfaction.

For the Chinese users, empathy had a significant impact on user satisfaction $(\mathrm{H} 6: \beta=0.217$, $\mathrm{p}<0.001)$. Collectivists usually have interdependent self-construal and more elaborate knowledge of others and therefore are more empathetic toward others (Gudykunst et al., 1996; Markus \& 
Kitayama, 1991; Oyserman et al., 2002). As such, the practice of empathy is valued in a collectivist community. For example, some Chinese drivers would provide free bottled water, or voluntarily help customers carry luggage to the trunk. Conversely, empathy exerted no impact on American satisfaction (H6: $\beta=0.084, p>0.05)$. Individualists tend to communicate in direct ways and convey information explicitly and unambiguously. Thus, Americans usually abide by the contract. The standard contract of ride-sharing services is that drivers pick up customers at the appointed time and place, and take them to their destinations. If drivers provide extra services that are not included in the contract, they may also expect tips from customers. Even a small part of empathy, such as carrying luggage for customers, could be considered an extra service in U.S.

Satisfaction was a strong predictor of continuance intention for both the Chinese $(H 7: \beta=0.596$, $\mathrm{p}<0.001)$ and the American $(\mathrm{H} 7: \beta=0.753, \mathrm{p}<0.001)$ users. This is consistent with existing findings (Bhattacherjee, 2001; Chen \& Qi, 2015; Wang, Ou, \& Chen, 2019). Consumers have expectations of ride-sharing services. When ride-sharing services meet or exceed users' expectations grounded in their experiences, they feel satisfied. Such satisfaction leads to loyalty. Therefore, satisfaction positively influenced users' continuance intention.

\subsection{Power Analysis}

Statistical power refers to the probability of rejecting the false null hypothesis (Cohen, 1988), and the false null hypothesis should be rejected to avoid a type II error. An increase in sample size also increases statistical power (Cohen, 1988). In this study, we chose a priori power analyses in G*power 3 to compute the necessary sample size before data collection (Cohen, 1988). Sample size (N) is computed as a function of the population effect size $\left(\mathrm{f}^{2}\right)$, the required power level $(1-\beta)$, and the prespecified significance level $\alpha$. We specified an effect size of 0.15 , which is considered medium according to Cohen's criteria. Furthermore, we specified the required power level of 0.8 ; and the significance level of 0.05 . The results showed that the necessary sample size for the research model in this study was 98. After data collection, we used post hoc power analyses to assess whether a statistical test in fact had a fair opportunity to reject an incorrect $\mathrm{H}_{0}$ (Cohen, 1988). In post hoc analyses, the statistical power (1- $\beta$ ) is computed as a function of the population effect size $\left(\mathrm{f}^{2}\right)$, the significance level $(\alpha)$, and the sample size $(\mathrm{N})$ used in a study. We specified the parameters for the complete, Chinese, and American data separately to run post hoc power analyses; and obtained statistical powers of 0.999 , 0.998 , and 0.939 respectively. Based on the above analysis, the statistical power of the three samples is above the threshold of 0.8 .

In addition, we also conducted PLS statistical analysis technique to analyze the statistical power of this model (Aguirre-Urreta \& Rönkkö,2015). The results indicated that a power of 0.765 for the path between platform assurance and satisfaction, a power of 0.268 for the path between platform responsiveness and satisfaction, a power of 0.855 for the path between tangibles and satisfaction, a power of 0.973 for the path between reliability and satisfaction, a power of 0.447 for the path between the assurance and satisfaction, a power of 0.802 for the path between reliability and satisfaction, and a power of 1.000 for the path between reliability and satisfaction. The majority of paths reached or came close to the targeted power level of 0.80 . Therefore, statistical power is not a critical issue in this paper.

\subsection{Multigroup Analysis}

\subsubsection{Measurement Invariance}

According to the MICOM procedure, all of the results met the compositional invariance criteria, and only three composites had equal mean values and variances, indicating partial measurement value (see Table 8). Therefore, we carried out a multigroup analysis by comparing standardized coefficients. 
Table 8. The compositional invariance and the equality of composite means and variances

\begin{tabular}{|c|c|c|c|}
\hline Composite & $c$ value $(=\mathbf{1})$ & $95 \%$ confidence interval & Compositional invariance? \\
\hline PAS & 0.999 & {$[0.978 ; 1.000]$} & Yes \\
\hline PRE & 0.999 & {$[0.975 ; 1.000]$} & Yes \\
\hline TAN & 0.998 & {$[0.980 ; 1.000]$} & Yes \\
\hline REL & 0.997 & {$[0.980 ; 1.000]$} & Yes \\
\hline ASS & 0.998 & {$[0.991 ; 1.000]$} & Yes \\
\hline EMP & 0.995 & {$[0.992 ; 1.000]$} & Yes \\
\hline SAT & 1.000 & {$[0.998 ; 1.000]$} & Yes \\
\hline $\mathrm{CI}$ & 0.997 & {$[0.994 ; 1.000]$} & Yes \\
\hline Composite & $\begin{array}{l}\text { Difference of the composite's } \\
\text { mean value }(=0)\end{array}$ & $95 \%$ confidence interval & Equal mean values? \\
\hline PAS & 1.041 & {$[-0.209 ; 0.213]$} & No \\
\hline PRE & 0.906 & {$[-0.210 ; 0.211]$} & No \\
\hline TAN & 0.155 & {$[-0.207 ; 0.209]$} & Yes \\
\hline REL & 0.253 & {$[-0.215 ; 0.212]$} & No \\
\hline ASS & 0.379 & {$[-0.209 ; 0.210]$} & No \\
\hline EMP & -0.021 & {$[-0.205 ; 0.205]$} & Yes \\
\hline SAT & 0.120 & {$[-0.204 ; 0.212]$} & Yes \\
\hline $\mathrm{CI}$ & 0.757 & {$[-0.199 ; 0.208]$} & No \\
\hline Composite & $\begin{array}{l}\text { Difference of the composite's } \\
\text { variance }(=0)\end{array}$ & $95 \%$ confidence interval & Equal variances? \\
\hline PAS & -0.524 & {$[-0.308 ; 0.329]$} & No \\
\hline PRE & -0.064 & {$[-0.328 ; 0.352]$} & Yes \\
\hline TAN & -0.092 & {$[-0.367 ; 0.383]$} & Yes \\
\hline REL & -0.314 & {$[-0.448 ; 0.437]$} & Yes \\
\hline ASS & -0.272 & {$[-0.358 ; 0.381]$} & Yes \\
\hline EMP & 0.493 & {$[-0.342 ; 0.344]$} & No \\
\hline SAT & -0.376 & {$[-0.465 ; 0.455]$} & Yes \\
\hline $\mathrm{CI}$ & -1.063 & {$[-0.494 ; 0.540]$} & No \\
\hline
\end{tabular}

\subsubsection{PLS-MGA Results}

In this study, the PLS-MGA results show that the Chinese and American users differed significantly in continuance decisions when they were satisfied with ride-sharing services (see Table 9). This finding is in accordance with prior research that confirms the moderating effect of IDV/COL on the relationship between satisfaction and repurchase intention for overall services (Frank et al., 2015). When satisfied with ride-sharing services, the American users had significantly stronger continuance 
Table 9. PLS-MGA results

\begin{tabular}{|l|l|l|l|l|l|l|}
\hline $\begin{array}{l}\text { Hypothesis } \\
\text { relationship }\end{array}$ & $\begin{array}{c}\text { Path coefficients } \\
\text { of Chinese }\end{array}$ & $\begin{array}{c}\text { Path } \\
\text { coefficients } \\
\text { of } \\
\text { Americans }\end{array}$ & $\begin{array}{c}\text { Path } \\
\text { coefficients- } \\
\text { diff } \\
\text { (I Chinese } \\
\text { group - } \\
\text { American } \\
\text { groupl) }\end{array}$ & \multicolumn{1}{|c|}{$\begin{array}{c}\mathbf{t}_{\text {parametric }} \\
\text { (Chinese group vs } \\
\text { American group) }\end{array}$} & Supported \\
\hline H8 & $\begin{array}{l}\text { SAT®CI } \\
\text { (moderating effect } \\
\text { of IDV/COL) }\end{array}$ & $0.596 * * *$ & $0.753 * * *$ & 0.157 & $2.280^{*}$ & Yes \\
\hline
\end{tabular}

intention than the Chinese users. While the superficial reason of this difference may be in the way how consumers use transportation between China and the US, the fundamental cause is also rooted in cultural values. In collectivism, decisions that reference how and what peers or groups expect usually require one to estimate or even guess the group norms, which results in a self-assessed group value that may or may not always be accurate. By contrast, individualists formulate assessments of self or personal needs that are more likely to be clear than guessing the peers. The stronger relationship between satisfaction and intention for Americans is likely the result of this self-assessment and actualization of one's own decisions based on that.

\section{IMPLICATIONS FOR RESEARCH AND PRACTICE}

This study provides several contributions for research. First, it is one of the first to develop a systemic understanding of ride-sharing service quality and enriches the ride-sharing research by investigating service quality-related factors shaping ride-sharing users' satisfaction. It also extends SERVQUAL to ride-sharing, which is needed as ride-sharing experience is a collective sale encounters of technology and humans. Few studies have examined the relationships between SERVQUAL factors and user satisfaction in ride-sharing. Therefore, our results will enrich the existing research on ride-sharing and improve the understanding of users' ride-sharing satisfaction and continuance intention.

Second, this research is also among the first studies to examine the differences in relationships among ride-sharing service quality factors, satisfaction, and continuance intention between China and the US. People from different cultures may have different attitudes toward the same service quality factors. Although prior studies have empirically validated the role of service quality in ride-sharing, they have usually sampled from a single country. Thus, their results might not be directly generalizable to countries with different cultures. Our work shows that culture difference does cause variations of how service quality dimensions affects satisfaction.

Third, this research contributes significantly to existing research by providing insights into how cultural values, especially IDV/COL, moderate the relationship between satisfaction and continuance intention. The difference between individualists and collectivists was empirically validated. Cultural value is a crucial factor that influences ride-sharing success.

The research outcomes not only reinforce the explanation of ride-sharing satisfaction and continuance intention but also have several strategic implications for ride-sharing practitioners and the global expansion of ride-sharing services. First, the results of this research illustrate how online and offline service quality factors drive ride-sharing users' satisfaction with ride-sharing services. For Chinese users, reliability, platform assurance, and empathy are significant factors affecting satisfaction. Therefore, Chinese ride-sharing companies should take measures to improve the quality of platform assurance and encourage users to learn more about this feature and use it. 
Additionally, Chinese ride-sharing companies could screen drivers by adding compassion and care into their recruiting requirements. Furthermore, Chinese ride-sharing companies should focus more on professional training, motivating drivers to actively increase their reliability. Tangibles are the crucial factor influencing American users' satisfaction. Therefore, American ride-sharing companies should also emphasize on comfort, spacious and other factors relating to enjoyment of the travel. The cars should also be clean and in good condition. A challenge for Chinese and American ridesharing companies is that it is difficult to control the behaviors of drivers because many drivers take ride-sharing as a part-time job and are not professionals. Ride-sharing companies now adopt user rating systems to collect information as a basis to evaluate the service quality of drivers. However, users tend to lack motivation to rate their ride-sharing experiences accurately. Therefore, this aspect remains critical for ride-sharing services. Second, the results show that satisfaction with ride-sharing services was a significant predictor of continuance intention for the both Chinese and American users. However, while the American users' satisfaction explained only $55.6 \%$ of the variance in continuance intention, the Chinese users' satisfaction explained only $35.5 \%$. Thus, Chinese ride-sharing companies or international ride-sharing companies that intend to provide services in China should take more measures to enhance users' continuance intention in addition to satisfaction. Similarly, ride-sharing service providers should understand that certain service quality factors predicting customer satisfaction and continuance intention are driven by cultural values. Thus, ride-sharing services should be designed in light of customer preferences with consideration of national cultural values.

\section{CONCLUSION}

This research attempts to understand user ride-sharing satisfaction and continuance intention from a service quality perspective. Despite the previously mentioned contributions, it has several limitations that provide future research opportunities. First, this study used only cross-sectional data. Future research could use longitudinal data to extend and validate this research model for ride-sharing continuance intention. Second, due to limited resources and time constraints, the amount of data collected is not large. Future studies could use big data technology to predict users' continuance intention more precisely. Finally, this study focuses only on the effect of ride-sharing service quality on satisfaction and continuance intention. Future research could study the influence of domain-specific value, such as social value, on satisfaction and continuance intention.

\section{ACKNOWLEDGMENT}

This research is supported by Zhejiang providence, China (Grant no. QJC1902003) and National Natural Science Foundation of China (Grant no. 72032008). 


\section{REFERENCES}

Agarwal, J., Malhotra, N. K., \& Bolton, R. N. (2010). A cross-national and cross-cultural approach to global market segmentation: An application using consumers' perceived service quality. Journal of International Marketing, 18(3), 18-40. doi:10.1509/jimk.18.3.18

Aguirre-Urreta, M., \& Rönkkö, M. (2015). Sample Size Determination and Statistical Power Analysis in PLS Using R: An Annotated Tutorial. Communications of the Association for Information Systems, 36, 3. doi:10.17705/1CAIS.03603

Ahmad, S. Z., Ahmad, N., \& Papastathopoulos, A. (2019). Measuring service quality and customer satisfaction of the small- and medium-sized hotels (SMSHs) industry: Lessons from United Arab Emirates (UAE). Tourism Review, 74(3), 349-370. doi:10.1108/TR-10-2017-0160

Alcántara-Pilar, J. M., Del Barrio-García, S., Crespo-Almendros, E., \& Porcu, L. (2017). Toward an understanding of online information processing in e-tourism: Does national culture matter? Journal of Travel \& Tourism Marketing, 34(8), 1128-1142. doi:10.1080/10548408.2017.1326363

Anderson, J. C., \& Gerbing, D. W. (1988). Structural equation modeling in practice: A review and recommended two-step approach. Psychological Bulletin, 103(3), 411-423. doi:10.1037/0033-2909.103.3.411

Ayaad, O., Alloubani, A., ALhajaa, E. A., Farhan, M., Abuseif, S., Al Hroub, A., \& Akhu-Zaheya, L. (2019). The role of electronic medical records in improving the quality of health care services: Comparative study. International Journal of Medical Informatics, 127, 63-67. doi:10.1016/j.ijmedinf.2019.04.014 PMID:31128833

Bagozzi, R. P., \& Yi, Y. (1988). On the evaluation of structural equation models. Journal of the Academy of Marketing Science, 16(1), 74-94. doi:10.1007/BF02723327

Belk, R. (2010). Sharing. The Journal of Consumer Research, 36(5), 715-734. doi:10.1086/612649

Belk, R. (2014). You are what you can access: Sharing and collaborative consumption online. Journal of Business Research, 67(8), 1595-1600. doi:10.1016/j.jbusres.2013.10.001

Bhattacherjee, A. (2001). Understanding information systems continuance:An expectation-confirmation model. Management Information Systems Quarterly, 25(3), 351-370. doi:10.2307/3250921

Boateng, H., Kosiba, J. P. B., \& Okoe, A. F. (2019). Determinants of consumers' participation in the sharing economy. International Journal of Contemporary Hospitality Management, 31(2), 718-733.

Brown, S. A., Venkatesh, V., \& Goyal, S. (2014). Expectation confirmation in information systems research: A test of six competing models. Management Information Systems Quarterly, 38(3), 729-756.

Chang, B.-L., Kao, H.-O., Lin, S.-J., Yang, S.-H., Kuo, Y.-W., \& Jerng, J.-S. (2019). Quality gaps and priorities for improvement of healthcare service for patients with prolonged mechanical ventilation in the view of family. Journal of the Formosan Medical Association, 118(5), 922-931. doi:10.1016/j.jfma.2018.09.019 PMID:30301580

Chasin, F., von Hoffen, M., Hoffmeister, B., \& Becker, J. (2018). Reasons for Failures of Sharing Economy Businesses. MIS Quarterly Executive, 17(3), 185-199.

Chen, Y., \& Zahedi, F. M. (2016). Individuals' internet security perceptions and behaviors: Polycontextual contrasts between the United States and China. Management Information Systems Quarterly, 40(1), 205-222. doi:10.25300/MISQ/2016/40.1.09

Cheng, X., Fu, S., \& de Vreede, G. (2018). A mixed method investigation of sharing economy driven carhailing services: Online and offline perspectives. International Journal of Information Management, 41, 57-64. doi:10.1016/j.ijinfomgt.2018.03.005

Cohen, J. (1988). Statistical power analysis for the behavioral sciences (2nd ed.). Erlbaum.

Cristobal-Fransi, E., Hernández-Soriano, F., Ferrer-Rosell, B., \& Daries, N. (2019). Exploring service quality among online sharing economy platforms from an online media perspective. Sustainability, 11(13), 3690. doi:10.3390/su11133690

Cusumano, M. A. (2017). The sharing economy meets reality. Communications of the ACM, 61(1), 26-28. doi: $10.1145 / 3163905$ 
Davidson, A., Habibi, M. R., \& Laroche, M. (2018). Materialism and the sharing economy: A cross-cultural study of American and Indian consumers. Journal of Business Research, 82, 364-372. doi:10.1016/j.jbusres.2015.07.045

DeLone, W. H., \& McLean, E. R. (2003). The DeLone and McLean model of information systems success: A tenyear update. Journal of Management Information Systems, 19(4), 9-30. doi:10.1080/07421222.2003.11045748

Diallo, M. F., \& Seck, A. M. (2018). How store service quality affects attitude toward store brands in emerging countries: Effects of brand cues and the cultural context. Journal of Business Research, 86, 311-320. doi:10.1016/j. jbusres.2017.08.017

Dong, Y., Wang, S., Li, L., \& Zhang, Z. (2018). An empirical study on travel patterns of internet based ridesharing. Transportation Research Part C, Emerging Technologies, 86, 1-22. doi:10.1016/j.trc.2017.10.022

Donthu, N., \& Yoo, B. (1998). Cultural influences on service quality expectations. Journal of Service Research, 1(2), 178-186. doi:10.1177/109467059800100207

Evans, J. R., \& Mathur, A. (2018). The value of online surveys: A look back and a look ahead. Internet Research, 28(4), 854-887. doi:10.1108/IntR-03-2018-0089

Fornell, C., \& Larcker, D. F. (1981). Evaluating structural equation models with unobservable variables and measurement error. JMR, Journal of Marketing Research, 18(1), 39-50. doi:10.1177/002224378101800104

Frank, B., Enkawa, T., \& Schvaneveldt, S. J. (2015). The role of individualism vs. collectivism in the formation of repurchase intent: A cross-industry comparison of the effects of cultural and personal values. Journal of Economic Psychology, 51, 261-278. doi:10.1016/j.joep.2015.08.008

Franque, F. B., Oliveira, T., Tam, C., \& Santini, F. D. O. (2020). A meta-analysis of the quantitative studies in continuance intention to use an information system. Internet Research, 31(1), 123-158. Advance online publication. doi:10.1108/INTR-03-2019-0103

Gefen, D., Rigdon, E. E., \& Straub, D. (2011). An update and extension to SEM guidelines for administrative and social science research. Management Information Systems Quarterly, 35(2), 3-14. doi:10.2307/23044042

Grand View Research. (2019). Ride sharing market size, share \& trends report ride sharing market size, share $\&$ trends analysis report by business model $(P 2 P, B 2 B, B 2 C)$, by commute type (corporate, short distance), by application, by region, and segment forecasts, 2019 - 2025. Retrieved from https://www.grandviewresearch. com/industry-analysis/ride-sharing-market

Gudykunst, W. B., Matsumoto, Y., Ting-Toomey, S., Nishida, T., Kim, K., \& Heyman, S. (1996). The influence of cultural individualism-collectivism, self-construals, and individual values on communication styles across cultures. Human Communication Research, 22(4), 510-543. doi:10.1111/j.1468-2958.1996.tb00377.x

Hair, J. F., Black, W. C., Babin, B. J., Anderson, R. E., \& Tatham, R. L. (2006). Multivariate data analysis. Pearson Prentice Hall.

Hair, J. F., Risher, J. J., Sarstedt, M., \& Ringle, C. M. (2019). When to use and how to report the results of PLSSEM. European Business Review, 31(1), 2-24. doi:10.1108/EBR-11-2018-0203

Henseler, J., Dijkstra, T. K., Sarstedt, M., Ringle, C. M., Diamantopoulos, A., Straub, D. W., \& Calantone, R. J. (2014). Common beliefs and reality about partial least squares: Comments on Rönkkö and Evermann (2013). Organizational Research Methods, 17(2), 182-209. doi:10.1177/1094428114526928

Henseler, J., Ringle, C. M., \& Sarstedt, M. (2015). A new criterion for assessing discriminant validity in variance-based structural equation modeling. Journal of the Academy of Marketing Science, 43(1), 115-135. doi:10.1007/s11747-014-0403-8

Henseler, J., Ringle, C. M., \& Sarstedt, M. (2016). Testing measurement invariance of composites using partial least squares. International Marketing Review, 33(3), 405-431. doi:10.1108/IMR-09-2014-0304

Heskett, J. L., Jones, T. O., Loveman, G. W., Sasser, W. E., \& Schlesinger, L. A. (1994). Putting the serviceprofit chain to work. Harvard Business Review, 72(2), 164-174.

Hofstede, G. (1980). Culture's consequences. Sage.

Hofstede, G. (1991). Cultures and organizations: Software of the mind. McGraw-Hall. 
Hofstede, G. (2001). Culture's consequences: Comparing values, behaviors, institutions and organizations across nations (2nd ed.). Sage Publications, Thousand Oaks.

Hofstede, G. (2010). Cultures and organizations: Software of the mind (3rd ed.). McGraw-Hall.

Hofstede, G. (2011). Dimensionalizing cultures: The Hofstede model in context. Online Readings in Psychology and Culture, 2(1). Advance online publication. doi:10.9707/2307-0919.1014

Hofstede, G., \& Minkov, M. (2010). Long- versus short-term orientation: New perspectives. Asia Pacific Business Review, 16(4), 493-504. doi:10.1080/13602381003637609

Hong, S., Choi, D., \& Chae, J. (2020). Exploring different airport users' service quality satisfaction between service providers and air travelers. Journal of Retailing and Consumer Services, 52(101917), 101917. doi:10.1016/j.jretconser.2019.101917

Huang, E. Y., Lin, S., \& Fan, Y. (2015). M-S-QUAL: Mobile service quality measurement. Electronic Commerce Research and Applications, 14(2), 126-142. doi:10.1016/j.elerap.2015.01.003

Huarng, K., \& Yu, M. (2019). Customer satisfaction and repurchase intention theory for the online sharing economy. Review of Managerial Science, 13(3), 635-647. doi:10.1007/s11846-018-0321-0

Hung, S. Y., Kang, T. C., Yen, D. C., Huang, A. H., \& Chen, K. (2012). A cross-cultural analysis of communication tools and communication outcomes. Journal of Global Information Management, 20(3), 55-83. doi:10.4018/ jgim.2012070103

Ju, Y., Back, K., Choi, Y., \& Lee, J. (2019). Exploring Airbnb service quality attributes and their asymmetric effects on customer satisfaction. International Journal of Hospitality Management, 77, 342-352. doi:10.1016/j. ijhm.2018.07.014

Kang, G. D., \& James, J. (2004). Service quality dimensions: An examination of Grönroos' s service quality model. Managing Service Quality, 14(4), 266-277. doi:10.1108/09604520410546806

Kang, M. (2018). Active users' knowledge-sharing continuance on social Q\&A sites: Motivators and hygiene factors. Aslib Journal of Information Management, 70(2), 214-232. doi:10.1108/AJIM-09-2017-0207

Khan, G. F., Sarstedt, M., Shiau, W.-L., Hair, J. F., Ringle, C. M., \& Fritze, M. P. (2019). Methodological research on partial least squares structural equation modeling (PLS-SEM). Internet Research, 29(3), 407-429. doi:10.1108/IntR-12-2017-0509

Kuswanto, A., Sundari, S., Harmadi, A., \& Hariyanti, D. A. (2020). The determinants of customer loyalty in the Indonesian ride-sharing services: Offline vs online. Innovation \& Management Review, 17(1), 75-85. doi:10.1108/INMR-05-2019-0063

Lam, D. (2007). Cultural Influence on proneness to brand loyalty. Journal of International Consumer Marketing, 19(3), 7-21. doi:10.1300/J046v19n03_02

Limayem, M., Hirt, S. G., \& Christy, M. K. C. (2007). How habit limits the predictive power of intention: The case of information systems continuance. Management Information Systems Quarterly, 31(4), $705-737$. doi: $10.2307 / 25148817$

Ma, L., Zhang, X., Ding, X., \& Wang, G. (2019). Risk perception and intention to discontinue use of ride-hailing services in China: Taking the example of DiDi Chuxing. Transportation Research Part F: Traffic Psychology and Behaviour, 66, 459-470. doi:10.1016/j.trf.2019.09.021

Maioli, H. C., de Carvalho, R. C., \& de Medeiros, D. D. (2019). SERVBIKE: Riding customer satisfaction of bicycle sharing service. Sustainable Cities and Society, 50(101680), 101680. doi:10.1016/j.scs.2019.101680

Malhotra, N. K., Agarwal, J., \& Shainesh, G. (2018). Does country or culture matter in global marketing? An empirical investigation of service quality and satisfaction model with moderators in three countries. In J. Agarwal \& T. Wu (Eds.), Emerging Issues in Global Marketing (pp. 61-91). Springer. doi:10.1007/978-3-319-74129-1_3

Malik, G., \& Rao, A. S. (2019). Extended expectation-confirmation model to predict continued usage of ODR/ ride hailing apps: Role of perceived value and self-efficacy. Information Technology \& Tourism, 21(4), 461-482. doi:10.1007/s40558-019-00152-3 
Markus, H. R., \& Kitayama, S. (1991). Culture and the self: Implications for cognition, emotion, and motivation. Psychological Review, 98(2), 224-253. doi:10.1037/0033-295X.98.2.224

Mattia, G., Guglielmetti Mugion, R., \& Principato, L. (2019). Shared mobility as a driver for sustainable consumptions: The intention to re-use free-floating car sharing. Journal of Cleaner Production, 237(117404), 117404. doi:10.1016/j.jclepro.2019.06.235

Meesala, A., \& Paul, J. (2018). Service quality, consumer satisfaction and loyalty in hospitals: Thinking for the future. Journal of Retailing and Consumer Services, 40, 261-269. doi:10.1016/j.jretconser.2016.10.011

Mirkovski, K., Jia, Y., Liu, L., \& Chen, K. (2018). Understanding microblogging continuance intention: The directed social network perspective. Information Technology \& People, 31(1), 215-238. doi:10.1108/ITP-072015-0168

Mousavi, R., Hazarika, B., Chen, K., \& Rienzo, T. (2020). The role of dissonance reduction and co-creation strategies in shaping smart service satisfaction - the case of Uber. Behavior \& Information Technology. Advance online publication.

Ocampo, L., Alinsub, J., Casul, R. A., Enquig, G., Luar, M., Panuncillon, N., \& Ocampo, C. O. (2019). Public service quality evaluation with SERVQUAL and AHP-TOPSIS: A case of Philippine government agencies. Socio-Economic Planning Sciences, 68(100604). doi:10.1016/j.seps.2017.12.002

Oliver, R. L. (1980). A cognitive model of the antecedents and consequences of satisfaction decisions. JMR, Journal of Marketing Research, 17(4), 460-469. doi:10.1177/002224378001700405

Oliver, R. L. (1999). Whence consumer loyalty? Journal of Marketing, 63(4_supp11), 33-44. doi: $10.1177 / 00222429990634$ s 105

Omar, M. S., Ariffin, H. F., \& Ahmad, R. (2016). Service quality, customers' satisfaction and the moderating effects of gender: A study of Arabic restaurants. Procedia: Social and Behavioral Sciences, 224, 384-392. doi:10.1016/j.sbspro.2016.05.393

Oyserman, D., Coon, H. M., \& Kemmelmeier, M. (2002). Rethinking individualism and collectivism: Evaluation of theoretical assumptions and meta-analyses. Psychological Bulletin, 128(1), 3-72. doi:10.1037/00332909.128.1.3 PMID:11843547

Pakurár, M., Haddad, H., Nagy, J., Popp, J., \& Oláh, J. (2019). The service quality dimensions that affect customer satisfaction in the Jordanian banking sector. Sustainability, 11(4), 1-24. doi:10.3390/su11041113

Parasuraman, A., Berry, L. L., \& Zeithaml, V. A. (1991). Refinement and reassessment of the SERVQUAL scale. Journal of Retailing, 67(4), 420-450.

Parasuraman, A., Zeithaml, V. A., \& Berry, L. L. (1985). A conceptual model of service quality and its implications for future research. Journal of Marketing, 49(4), 41-50. doi:10.1177/002224298504900403

Parasuraman, A., Zeithaml, V. A., \& Berry, L. L. (1988). SERVQUAL: A multiple-item scale for measuring consumer perceptions of service quality. Journal of Retailing, 64(1), 12-40.

Parasuraman, A., Zeithaml, V. A., \& Malhotra, A. (2005). E-S-QUAL: A multiple-item scale for assessing electronic service quality. Journal of Service Research, 7(3), 213-233. doi:10.1177/1094670504271156

Priporas, C., Stylos, N., Rahimi, R., \& Vedanthachari, L. N. (2017). Unraveling the diverse nature of service quality in a sharing economy. International Journal of Contemporary Hospitality Management, 29(9), 2279-2301. doi:10.1108/IJCHM-08-2016-0420

Reichheld, F. F., \& Sasser, W. E. (1990). Zero defections quality comes to services. Harvard Business Review, 68(5), 103-109. PMID:10107082

Salomon, S., \& Staff, W. (2015, June 25). Why Americans buy bigger cars than the rest of the world. Retrieved from https://www.boston.com/cars/news-and-reviews/2015/06/25/why-americans-buy-bigger-cars-than-therest-of-the-world

Santos, J. (2003). E-service quality: A model of virtual service quality dimensions. Managing Service Quality, 13(3), 233-246. doi:10.1108/09604520310476490 
Shang, D., \& Wu, W. (2017). Understanding mobile shopping consumers' continuance intention. Industrial Management \& Data Systems, 117(1), 213-227. doi:10.1108/IMDS-02-2016-0052

Shao, Z., Li, X., Guo, Y., \& Zhang, L. (2020). Influences of service quality in sharing economy: Understanding customers' continuance intention of bicycle sharing. Electronic Commerce Research and Applications, 40(100944), 100944. doi:10.1016/j.elerap.2020.100944

Shiau, W.-L., \& Chau, Y. K. (2016). Understanding behavioral intention to use a cloud computing classroom: A multiple model-comparison approach. Information \& Management, 53(3), 355-365. doi:10.1016/j.im.2015.10.004

Shiau, W.-L., Sarstedt, M., \& Hair, J. F. (2019). Internet research using partial least squares structural equation modeling (PLS-SEM). Internet Research, 29(3), 398-406. doi:10.1108/IntR-10-2018-0447

Souri, M. E., Sajjadian, F., Sheikh, R., \& Sana, S. S. (2018). Grey SERVQUAL method to measure consumers' attitudes towards green products - A case study of Iranian consumers of LED bulbs. Journal of Cleaner Production, 177, 187-196. doi:10.1016/j.jclepro.2017.12.105

Su, D. N., Nguyen-Phuoc, D. Q., \& Johnson, L. W. (2019). Effects of perceived safety, involvement and perceived service quality on loyalty intention among ride-sourcing passengers. Transportation. Advance online publication. doi:10.1007/s11116-019-10058-y

Tan, F. T., Cahalane, M., Tan, B. C., \& Englert, J. (2017). How GoGet CarShare's Product-Service System is Facilitating Collaborative Consumption. MIS Quarterly Executive, 16, 265-277. http://misqe.org/ojs2/index. php/misqe/article/view/800

Tan, F. T., Tan, B., \& Lu, A. (2017). Delivering Disruption in an Emergent Access Economy: A Case Study of an E-Hailing Platform. Communications of the Association for Information Systems, 41, 497 - 516. https:// aisel.aisnet.org/cais/vol41/iss1/22/

Vanderschuren, M., \& Baufeldt, J. (2018). Ride-sharing: A potential means to increase the quality and availability of motorised trips while discouraging private motor ownership in developing cities? Research in Transportation Economics, 69, 607-614. doi:10.1016/j.retrec.2018.03.007

Wang, W., Ou, W., \& Chen, W. (2019). The impact of inertia and user satisfaction on the continuance intentions to use mobile communication applications: A mobile service quality perspective. International Journal of Information Management, 44, 178-193. doi:10.1016/j.ijinfomgt.2018.10.011

Wang, X., Lin, X., \& Liu, Z. (2019). Understanding Consumers' Post-Adoption Behavior in sharing economy services. Journal of Computer Information Systems, 59(2), 1-10. doi:10.1080/08874417.2019.1571458

Wang, Y., Gu, J., Wang, S., \& Wang, J. (2019). Understanding consumers' willingness to use ride-sharing services: The roles of perceived value and perceived risk. Transportation Research Part C, Emerging Technologies, 105, 504-519. doi:10.1016/j.trc.2019.05.044

Wen, C., Qin, G. H., Prybutok, V. R., \& Blankson, C. (2012). The role of national culture on relationships between customers' perception of quality, values, satisfaction, and behavioral intentions. The Quality Management Journal, 19(4), 7-23. doi:10.1080/10686967.2012.11918080 
Wen-Lung Shiau received the MS in Computer Science from Polytechnic University, New York, U.S. in 1995 and the PhD degree from the National Central University, Chung-Li, Taiwan in 2006. He is a professor in the Department of Business Administration of Zhejiang University of Technology, Hangzhou City, Zhejiang, China. He has published 63 journal papers and many high cited articles in the Web of Science, Top 1\% by citations/field in Clarivate Analytics (ESI). His current research interests include data analysis, marketing, and E-business. His papers have been published or accepted in Internet Research, IM\&DS, Scientometrics, IT\&P, IJIM, EJIS, DSS, I\&M and among others. Hao Chen received the master's degree in Economics and Computer Science in Dresden University of Technology, Dresden, Germany in 2010, and works for his PhD degree in Zhejiang University of Technology, Hangzhou City, Zhejiang, China. He focuses his interests in sharing economy and electronic business. His works have been published in Pacific Asia Conference on Information Systems (PACIS) and many high-quality Chinese journals.

Kuanchin Chen is Professor of Computer Information Systems, Director of the Center for Business Analytics, and John W. Snyder Fellow at Western Michigan University. His research interests focus on electronic business, data analytics, social networking, privacy \& security, online behavioral issues, and human computer interactions. He has published in many academic journals, including Information Systems Journal, Decision Support Systems, Information \& Management, IEEE Transactions on Systems, Man, and Cybernetics, International Journal of Information Management, Journal of Database Management, Internet Research, Communications of the Association for Information Systems, Electronic Commerce Research and Applications, Journal of Global Information Management, DATA BASE for Advances in Information Systems, Information processing \& Management, International Journal of Medical Informatics, and Tourism Management. He has been an editor, associate editor, and editorial member of several scholarly journals. Dr. Chen is also a recipient of several research and teaching awards, including awards given by scholarly journals \& conferences, department, college, university and U.S. Fulbright program. He has frequently been invited to give research talks at universities, government agencies and other institutions.

Yi-Hung Liu received the Ph.D. degree in information management from National Central University, Taiwan, in December 2014. Since 2020, he has been with the Department of Computer Science and Information Management, Soochow University, Taipei, Taiwan, where he is currently an Assistant Professor. He has been a Visiting Scholar with the Department of Management Information Systems, University of Arizona, USA, in 2013. His research interests include text mining, machine learning, E-commerce, social networks analysis, and healthcare.

Felix Ter Chian Tan is a Researcher and Senior Lecturer of Information Systems at the University of New South Wales (UNSW) Business School. His research interests include Digital Platforms, Information Systems for Good, Sports Digitalization, E-Commerce, and Enterprise Systems. He actively examines these interests in the context of Digital Transformation for business and social change. His research work has been published in various academic and practitioner journals such as Information Systems Journal, Information and Management, MISQ Executive, Communications of the AIS, International Journal of Information Management and Australasian Journal of Information Systems. Dr Tan is presently serving as Associate Editor of Information Systems Journal, Journal of Strategic Information Systems and Information and Management. Dr Tan is presently serving on the SAP Academic Alliance Board (Asia-Pacific and Japan). Dr Tan is the founder of UNOVA, a transdisciplinary research and development lab at UNSW. 